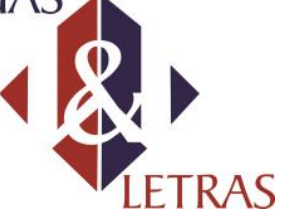

\title{
Descubriendo A Un Héroe: La Historia De Un Padre Combatiente En La Obra Las Hojas Muertas De Bárbara Jacobs
}

\author{
Discovering a hero: the story of a fighter father in Bárbara Jacobs's \\ novel Las hojas muertas
}

\author{
Benedetta Belloni* \\ * Università Cattolica del Sacro Cuore,UNICATT, Milano-Italia, 1, 20123, e-mail: \\ benedetta.belloni@unicatt.it
}

RESUMEN: La novela de Bárbara Jacobs Las hojas muertas da voz a una historia silenciada, la de Emile Jacobs, un hombre americano de origen libanés que se unió voluntario a las filas de las Brigadas Internacionales para luchar en la Guerra Civil española en 1937. El objetivo de este trabajo es el de recuperar, gracias a la escritura de la hija, la memoria de la experiencia de un ex-combatiente que, desde su condición real de fracasado y perdedor, se convierte en un héroe dentro de la obra literaria.

PALABRAS-CLAVE: Bárbara Jacobs; literatura mexicana; Emile Jacobs; Guerra Civil española; memoria.

ABSTRACT: Bárbara Jacobs's novel Las hojas muertas gives voice to the silenced history of Emile Jacobs, an American of Lebanese origin who joined as a volunteer the International Brigades in order to fight in the Spanish Civil War in 1937. The aim of this study is to recover, through his daughter's work, the memory of an ex-fighter's experience. In the literary work the man, who suffers in reality the condition of the failure, becomes a hero in the novel, through the childish eyes of the narrator.

KEYWORDS: Bárbara Jacobs; Mexican Literature; Emile Jacobs; Spanish Civil war; memory.

\section{INTRODUCCIÓN}

Las hojas muertas es una novela de la escritora mexicana Bárbara Jacobs ${ }^{1}$ en la que se cuenta básicamente la saga de una familia de origen mexicano-libanés. Uno de los personajes que más destacan en la narración es sin duda la figura del padre de la protagonista: en efecto, muchas porciones de la obra están intensamente conectadas con el proyecto autoral de descubrir la esencia de un individuo tan extraordinario. "Fui tomando notas de mi papá y de su historia", cuenta la escritora, "había mucha gente que me decía: «Tienes que escribir sobre tu papá». Lo que él hizo en la vida es algo que

\footnotetext{
${ }^{1}$ La obra fue publicada en 1987 por la Editorial Era y reeditada diez años después por la Editorial Alfaguara. La obra le brindó a la escritora el Premio Xavier Villaurrutia en el mismo año de publicación con Era. La escritora nació en Ciudad de México en 1947.
}

Volume 18

Número 40 


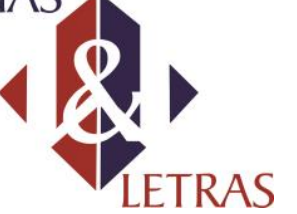

e-ISSN: 1981-4755

DOI: $10.5935 / 1981-4755.20170016$

objetivamente merece ser contado, merece ser rescatado, porque ya no hay alguien así” (Padilla, 2012). En el segundo capítulo de la obra, entonces, se da voz a una historia silenciada, la de Emile Jacobs, un americano de origen libanés que se unió voluntario a las filas de las Brigadas Internacionales para luchar en la Guerra Civil española en 1937. El largo fragmento de la novela dedicado al cuento de la experiencia del padre como soldado se construye como un relato de coraje y orgullo que se convierte, en definitiva, en testimonio y homenaje. El objetivo de este trabajo es entonces el de recuperar, gracias a la escritura de la hija, la memoria de la experiencia de un combatiente que, todavía en la etapa final de su vida, se siente fracasado y perdedor, una condición que el mismo Jacobs atestigua en la película documental Extranjeros de sí mismos dirigida por Javier Rioyo y José Luis López-Linares en 2001.

\section{EN BUSCA DE PAPÁ: RETRATO DE UN HOMBRE DESCONOCIDO}

Bárbara Jacobs se hace cargo en su novela de una doble operación literaria. Por un lado, la escritora consigue construir paso a paso un álbum narrativo donde relata la historia de la emigración de una familia de origen libanés asentada primero en Estados Unidos y luego en México. Este procedimiento le lleva a la realización de un diario donde la memoria va construyéndose colectivamente, a través de los más íntimos recuerdos de su conjunto familiar, mediante los cuales la escritora intenta recobrar las raíces de su propia identidad. Por el otro, la novela tiene el propósito de indagar y descubrir a la figura del padre desde diferentes perspectivas. El objetivo de la autora está perfectamente delineado a partir de la primera línea de la novela: "Ésta es la historia de papá, papá de todos nosotros” (JACOBS, 1997, 11). La determinación de ir recuperando a la figura del padre surge de la necesidad de conocer más de cerca a una persona de la que la protagonista y sus hermanos saben poco o nada. Ellos desconocen por completo las experiencias que su padre había vivido antes de que él se casara con su madre y antes de que ellos nacieran. En particular, lo que los hermanos ignoran son las vivencias enlazadas con la participación del padre como soldado en la Guerra Civil española. Una parte de la novela consigue, en fin, dar respuestas a unos interrogantes que por mucho tiempo tuvieron locos a los niños de casa, intentando poner de manifiesto lo que estaba oculto y desvelando así las incógnitas nacidas y maduradas en el ambiente familiar.

El padre de la joven protagonista, cuyo nombre no se deja manifiesto en la 


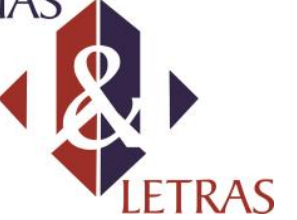

narración, está descrito como un hombre insólito y silencioso, enigmático en su conducta. Es norteamericano de origen libanés, como su esposa. Hotelero de profesión, dedica todo su tiempo a la lectura: posee, de hecho, muchos libros en su oficina y en su casa. También le gusta mucho jugar al bridge o al ajedrez con sus amigos italianos y polacos que, como él, viven en territorio mexicano. De vez en cuando, con su Cadillac, se marcha a Estados Unidos para renovar los papeles y legalizar su estancia en México. El hombre tiene un carácter muy firme, se enoja frecuentemente y duerme desnudo. Con sus hijos habla solo inglés y, cuando les dirige palabra, les hace reproches. Al enfadarse por algo, se cierra con llave en su cuarto, un lugar donde intenta distanciarse de frecuentes estados de agotamiento emocional. A la hora de cenar, el hombre nunca deja nada en el plato porque, como afirma la madre, "sabía lo que era pasar hambre" (JACOBS, 1997, 27). A pesar de la compleja relación que los une, el amor que los hijos sienten hacia él es profundo y está atestiguado en muchas ocasiones en la novela: "Queríamos mucho a papá y mamá", afirma la protagonista, “aunque a papá no lo conociéramos tan a fondo como a mamá porque con él casi no estábamos y él casi nunca nos contaba nada" (JACOBS, 1997, 38)².

La percepción de que los hijos van creciendo con la imagen mitificada de su padre se desprende con toda claridad en la novela. En efecto el 'nosotros' narrador construye, mediante su ingenua mirada infantil, la representación de un hombre que tiene contornos casi legendarios. No obstante eso, la figura del padre se presenta para sus hijos esencialmente como un hombre distante y extraño. El silencio es la marca principal que caracteriza la insólita relación entre ellos. Además, la amargura que el sujeto experimenta de forma profunda en la segunda etapa de su vida se expresa esencialmente a través de cierta actitud de aislamiento que le aleja de sus afectos más cercanos. Se evidencia por tanto en el hombre una incapacidad de compartir dentro del ámbito familiar las experiencias vividas en la guerra, una conducta que le orienta hacia una honda y momentánea crisis de comunicación. La socióloga argentina Elizabeth Jelin comenta que "los acontecimientos traumáticos conllevan grietas en la capacidad narrativa, huecos en la memoria" $(2002,28)$. El origen del silencio del padre, por tanto, se imputa claramente a las fisuras, a las erosiones que el impacto con la guerra le produjo en su interior, dejándole profundas heridas que le negaron inicialmente la

\footnotetext{
${ }^{2}$ Otras manifestaciones de afecto se atestiguan en las siguientes palabras: "Papá nos caía muy bien, aunque se enojara y aunque no nos hablara y aunque sólo se la pasara leyendo o jugando bridge con sus amigos italianos y polacos y ajedrez con el cabrón del General [...]" (JACOBS, 1997, 48), "Querido papá te necesitamos, Querido papá te queremos, Querido papá te extrañamos [...]" (JACOBS, 1997, 49).

Volume 18

Número 40
} 


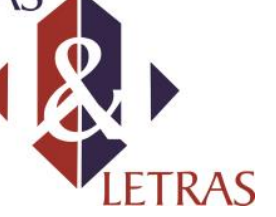

oportunidad de aceptar el dolor, atravesarlo y compartirlo luego con los demás.

En el primer capítulo de la obra, la autora/narradora/protagonista, relatando la historia con su voz infantil, logra muy bien que el lector se identifique disfrutando con el juego de resolver el misterio en torno a la figura del padre y a su implicación en alguna experiencia de guerra. "Un día el menor de nosotros se animó", cuenta la protagonista, “y le preguntó a mamá si papá había perdido o ganado en la guerra en la que había pasado hambre y mamá tuvo que contarle la verdad" (JACOBS, 1997, 27). Al responder a la pregunta, la madre consigue apaciguar por un momento una curiosidad que, en cambio, se nota crecer con intensidad a lo largo de las páginas del primer capítulo. Afirma a este propósito la protagonista: "Bueno, a todo esto fue llegando el momento en que a nosotros nos empezó a dar cada vez más curiosidad saber todo eso de «antes» en la vida de papá porque ya nos habíamos cansado un poco de imaginar cosas de su vida" (1997, 47-48). El fuerte deseo de descubrir informaciones sobre las hazañas de la vida de 'antes' del padre lleva a los hermanos incluso a entrometerse en los espacios más íntimos de su mamá, dando ojeadas a un cajón, que siempre está cerrado con llave, donde ella guarda objetos y recuerdos privados enlazados con su marido y su relación de pareja. Un fragmento preciso de la novela relata, de hecho, el hallazgo en ella de “cartas de papá a mamá y de ella a él y un álbum de fotografías de papá en la guerra de la que hablaba mamá. En esas fotografías los camaradas de papá y papá llevaban puesto uniforme de ningún ejército pero si todos alpargatas aunque fuera invierno y hubiera nieve" $(1997,29)$.

La implicación del padre en la experiencia bélica está aún más certificada por la visita que el señor Carpenter, uno de los camaradas americanos del padre, hace un día a su viejo compañero en su casa en México: "Mamá nos contaba que Jack era amigo de papá de antes", relata la narradora, “y que precisamente con él se había ido a la guerra y que por eso tenían muchas cosas de qué hablar y no debíamos hacer ruido ni entrar a donde estuvieran a interrumpirlos porque se la pasaban recordando cosas de cuando habían estado en la guerra en la que habían pasado hambre y en la que, según sabíamos nosotros a escondidas por las fotografías del álbum que mamá guardaba bajo llave como un tesoro muy personal, habían usado alpargatas" (1997, 47). La sensación de quedarse al margen no consigue rendir a sus hijos que estaban "ávidos de información de papá" $(1997,48)$ y necesitaban conocer ya toda la historia encubierta. La verdad sobre la vida de su padre irá desvelándose solamente unos años después. Cuenta la narradora que la reserva se rompe precisamente "cuando fuimos creciendo y fuimos sabiendo más entre 


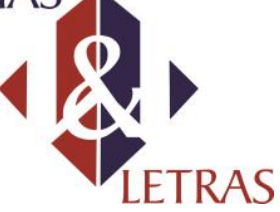

e-ISSN: 1981-4755

DOI: $10.5935 / 1981-4755.20170016$

otras cosas porque papá empezó a platicar nos dimos cuenta de que lo que sabíamos era poco y no tan exacto" (1997, 55). El segundo capítulo de la novela se configura, entonces, como el lugar donde el misterio se aclara y como el espacio donde se hace posible recuperar los más íntimos recuerdos de una figura extraordinaria que, hasta el momento de la escritura de la obra, la historia oficial ignoraba y que, por tanto, no podía reconocer.

\section{EL SILENCIO ROTO: HISTORIA DE UN COMBATIENTE EN LA GUERRA CIVIL ESPAÑOLA}

El itinerario biográfico del padre empieza en América del Norte, más precisamente en Nueva York donde nació el 20 de diciembre de 1909 en un área del bajo Manhattan denominado 'Pequeña Siria', poblado entre fines del 1800 y mediados del 1900 por emigrantes que eran mayormente de origen árabe. El padre había crecido en una familia de libaneses en la que se cultivaban y se preservaban el idioma, las costumbres, los valores y las tradiciones religiosas de su país de procedencia. Al moverse a Flint, una pequeña ciudad del estado de Michigan, el joven libanés empieza a convertirse en más americano: aprende inglés, asiste a un colegio y trabaja como repartidor de periódicos en bicicleta para ganarse algún dinerillo. Más adelante, entra en el Flint Junior College y, paralelamente, consigue diferentes trabajos. Hasta que decide volver a Nueva York para estudiar periodismo en la universidad. Unos nuevos amigos lo introducen en un restringido círculo de intelectuales de la época, donde conoce al escritor Waldo Frank y también a algunos periodistas de la famosa revista The New Yorker. Así que, gracias a los recientes contactos adquiridos, surge para él la oportunidad de convertirse en 1934 en el corresponsal extranjero desde Moscú para un nuevo periódico neoyorquino, The Monthly Review. Al mismo tiempo, colabora en la capital rusa con el diario Moscow Daily News y la revista International Review.

Al volver de la Unión Soviética, se afilia al partido comunista y decide unirse a la Brigada Lincoln para ir a combatir en la Guerra Civil española al lado de la República. A finales de 1936, se embarca como voluntario junto a otros camaradas (Ed Lending, Jack Carpenter, Russell Dell, el Capitán Merriment) y llega a Sète, en Francia. $\mathrm{Al}$ desembarcar en las costas francesas, es encarcelado y soltado de la prisión solo unos meses después. En Perpiñán, los camaradas de la Brigada Lincoln se unen con los de las Brigadas Internacionales. Tras algunos intentos fracasados, llegan a España cruzando 


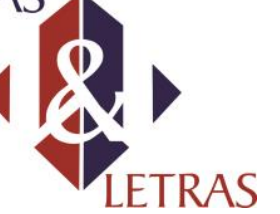

e-ISSN: 1981-4755

DOI: $10.5935 / 1981-4755.20170016$

los Pirineos a pie. El padre de la narradora es uno de los primeros a pisar tierra española: en ese tiempo tiene 27 años y demuestra ser un joven fuerte y muy determinado. Una vez en España, los voluntarios americanos del quinto regimiento de la Brigada Lincoln reciben un mes de entrenamiento en la infantería. Emile es designado al servicio de los transportes y empieza su cargo de conductor de ambulancias. Su misión es la de transportar heridos y llevar en los frentes equipo y alimentos. En la más cruenta batalla de toda la Guerra Civil, la ofensiva del Ebro, el americano conduce la ambulancia sin interrupción transportando más de 150 heridos en solo 48 horas. Después del enfrentamiento, la Brigada Lincoln se reduce mucho en número de hombres y también los voluntarios de los otros batallones son cada vez menos. En 1938 se establece un plan de repatriación de los extranjeros de las Brigadas Internacionales. Emile no vuelve a Estados Unidos hasta que no logra recuperarse de un fuerte ataque de malaria que le obliga a quedarse en el hospital. A mediados del año 1939, Jacobs desembarca finalmente en Nueva York.

En Las hojas muertas, el límite entre lo ficcional y lo no ficcional es muy impreciso: por tratarse de un texto de carácter (auto)biográfico, la novela otorga, dentro de un contexto de ficción, detalles potencialmente verificables. Al centrarse en la experiencia de la guerra, en particular, la autora refiere no sólo los recuerdos de su progenitor, sino que describe también la historia con datos reales, reproduciendo de esta forma espacios temporales y geográficos bien precisos. Está claro entonces que la historia juega un papel fundamental en la trama planteada por la autora: a pesar de eso, es evidente que en la obra la literatura trabaja para sobrepasar los límites que el discurso histórico posee como género en una labor de reconstrucción de una memoria individual que necesita espacios también para la reflexión y la expresión de los sentimientos.

En cuanto al acomodo de los datos históricos dentro del proceso de reconstrucción de la vida de 'antes' de su papá, el trabajo de la autora es puntual. El uso de los detalles históricos responde a la voluntad de la escritora de hacer emerger un marco verosímil donde la experiencia individual de su padre va desarrollándose: la reproducción de un contexto socio-histórico bien determinado le proporciona entonces a la escritora la oportunidad para que la memoria personal de su padre pueda emerger con más autenticidad. La narradora, de hecho, menciona fechas precisas, indica lugares bien determinados y también cita nombres de personas que protagonizaron de verdad el conflicto. Elementos fácilmente revisables mediante la consulta de documentos de 


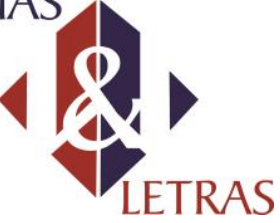

e-ISSN: 1981-4755

DOI: $10.5935 / 1981-4755.20170016$

archivo o manuales de historia ${ }^{3}$. Muy curioso es el manejo de esta operación narrativa a cargo de la voz infantil de la narradora que delinea sí de forma precisa los hechos históricos, pero mezclando la narración de ellos con comentarios triviales, propios de una niña. Es el caso, por ejemplo, del momento en el que la narradora cuenta la creación de la Brigada Lincoln:

El propósito de las reuniones de la sección del Partido Comunista al que papá y Ed se habían unido era organizarse para ir a luchar a España y se fueron organizando y entonces se constituyó la Brigada Lincoln y papá formó parte de ella desde el principio junto con Ed y también Jack, Jack Carpenter, con su quijada de Popeye desde entonces, Y Dell, otro amigo de papá que les llevaba diez años a los demás y era alto y delgado. [...] Para entonces papá y Ed compartían un cuarto de azotea estaban juntos todo el tiempo y hablaban mucho del Partido [...] y hablaban de lo mismo con sus camaradas ahí en la azotea y a veces llegaba Alvah Bessie y de eso hablaban y a papá Alvah le caía bien aunque a Ed no tanto (JACOBS, 1997, 80-81).

La elección de esta peculiar modalidad estilística le ayuda a la autora, en efecto, a proporcionarle al lector una visión menos agotadora de los eventos trágicos que se van relatando a lo largo de las páginas del capítulo. Además, la introducción de unas intervenciones nacidas de la mirada cándida de una niña evitan el riesgo de transformar el relato en una fría exposición de datos históricos. A veces, las anotaciones propuestas por la protagonista parecen chocar con la situación que está describiendo, como en el caso del relato de la experiencia de la detención de su padre en Francia:

Cuando llegaron a Sète en Francia no les permitían bajar del barco pues el cónsul norteamericano que los recibió les dijo que el propósito de su viaje era ilegal [...] y finalmente desembarcaron aunque sólo para que las autoridades francesas los detuvieran y los encarcelaran. [...] Los soltaron algunos meses después. Para entonces papá ya había comido alcachofas por primera vez y había hecho la reflexión de que se empleaba demasiado trabajo para comerlas para que al final en realidad no se les comiera casi nada. Ya había terminado el invierno de 1936 y empezaba 1937 y los voluntarios se iban reuniendo y algunos se iban quedando atrás y se dispersaban y se olvidaban de una vez de la misión que los había hecho partir [...]

\footnotetext{
${ }^{3}$ Sobre la participación de los norteamericanos en la Guerra Civil española y, en particular, sobre el batallón de la Brigada Abraham Lincoln, se remite a las siguientes obras: Alvah Bessie, Men in Battle, San Francisco, Chandler and Sharp, 1975 y Peter N. Carroll, La odisea de la Brigada Abraham Lincoln: los norteamericanos en la Guerra Civil Española, trad. de Mary Kay MacCoy, Sevilla, Editorial Espuela de Plata, 2005. Asimismo recordamos que en la web ALBA (Abraham Lincoln Brigade Archives: http://www.alba-valb.org/about-us/) es posible encontrar mucha información sobre los voluntarios que formaron parte de la Brigada Lincoln. La web también recoge datos sobre Emile Jacobs y los amigos americanos citados en la novela. Para más información sobre las Brigadas Internacionales, se remite a: Fernando Schwartz, La internacionalización de la Guerra Civil Española, Barcelona, Ariel, 1971.
}

Volume 18

Número 40 


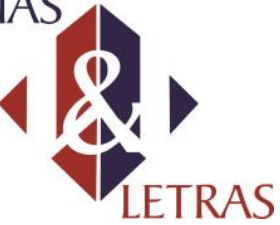

(JACOBS, 1997, 82).

No obstante la presencia de algunos datos precisos en la narración, la reproducción del contexto de la experiencia de Emile Jacobs en la Guerra Civil española coincide solo lacónicamente con la realidad del conflicto: la narradora no puede restituir exactamente las vivencias bélicas del padre tal como ocurrieron pero, sin embargo, sí que integra en el relato una visión que abarque la descripción de la guerra como una impactante experiencia de vida, declinada en sus matices positivos y negativos.

Por lo que atañe a los aspectos buenos que la guerra también puede implicar, en su relato la narradora fija muchas veces la atención en las profundas relaciones interpersonales que su padre logró establecer a lo largo de su experiencia en el campo de batalla. Como es sabido, las situaciones de conflicto promueven la cohesión entre los individuos puesto que, frente a un alto riesgo personal, aumenta la solidaridad entre los compañeros del mismo bando. En tiempos de guerra se crean, entonces, lazos afectivos muy fuertes, relaciones íntimas que, únicamente en los casos más afortunados, se prolongan hasta el periodo de la posguerra ${ }^{4}$. Eso es lo que pasó también entre los camaradas del batallón de la Brigada Lincoln:

[...] y la guerra seguía y los camaradas de papá iban muriendo y papá seguía transportando heridos y equipo y alimento en su ambulancia destartalada. Pero esto no era lo único que hacían papá y sus amigos pues en el medio de la guerra encontraban tiempo para encontrarse y hacerse más amigos y en un momento dado un compañero le enseñó a papá en plena guerra a jugar ajedrez y ahora empezó a entender a papá de que se trataba el juego del que él había escrito en Moscú para el Moscow Daily News y del que ahora un amigo americano como él y de nombre Neider le enseñaba los primeros pasos. [...] y fue a dar a Murcia y una vez ahí buscó el cuartel general de las Brigadas y se presentó y fue entonces cuando de casualidad se encontró con su viejo amigo Ed y entonces los dos se abrazaron y no dejaban de abrazarse en plena guerra (JACOBS, 1997, 86-88).

Sin embargo, la cruel realidad de la trinchera puede de repente convertir las sensaciones positivas en dolidas emociones de angustia. El conflicto se configura como una situación extremadamente intensa que hace aflorar todos los sentimientos del ser humano. De forma particular, la cara más triste y atormentada de la guerra está retratada por la narradora cuando intenta describir el dolor del padre al ver sus amigos caer en el campo de batalla. Es precisamente en esas circunstancias cuando empieza, según el

\footnotetext{
${ }^{4}$ En la novela se habla sobre todo de las amistades duraderas entre el padre Emile y dos compañeros suyos de la Brigada: Jack Carpenter y Ed Lending. En algunos episodios se cuentan las visitas que Carpenter hacía a Emile y las visitas de Emile a Ed en su casa en Miami (JACOBS, 1997, 132-133).

Volume 18

Número 40
} 


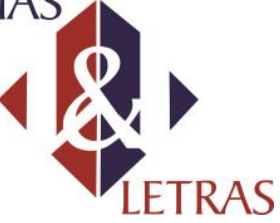

e-ISSN: 1981-4755

DOI: $10.5935 / 1981-4755.20170016$

punto de vista de la hija, el proceso de enmudecimiento originado como severa reacción emocional a un trauma psicológico tan extremo como fue, en particular, el testimonio de la muerte de su amigos:

Pero la guerra era más fea y más triste que esto y cuando papá empezó a ver morir a sus compañeros se fue horrorizando y entristeciendo y nosotros creemos que ahí empezó también a preferir guardar silencio que hablar. El Capitán Merriment, cuyo nombre significaba júbilo y con quien papá se había embarcado en Nueva York y con quien había llegado a Sète y con quien también en Sète había sido encarcelado un día cayó y la suya fue una de las primeras muertes que papá sintió de forma personal y luego siguieron otras y las peores de éstas tuvieron lugar en Almería (JACOBS, 1997, 89).

Acerca del estrés post-traumático causado por la guerra, recuerda Ruiz-Vargas que "existen pocas dudas acerca del papel potenciador de la emoción sobre la memoria. [...] parece que no existe un ingrediente más eficaz que los sentimientos, los afectos, las emociones en general, para que las experiencias humanas queden grabadas a fuego en nuestra memoria” (RUIZ-VERGAS, 2006, 8). Sobre la experiencia bélica, en particular, afirma el investigador que "la misma sensación de sentirse atados a los recuerdos lacerantes de la tragedia es frecuentemente referida por los soldados con experiencia de combate", subrayando además que "la reexperiencia de la situación traumática a través, fundamentalmente, de recuerdos intrusos que no dejan de atormentar a las víctimas es, precisamente, el síntoma dominante" (RUIZ-VERGAS, 2006, 11). Un trastorno emotivo inacabable, entonces, que la narradora registra también en la última parte de la novela cuando el padre, ya anciano, al recordar las pérdidas de sus compañeros en el conflicto, se pone a llorar:

Por esos días pasaron una serie de televisión en conmemoración de la Guerra Civil de España y papá se encerraba a verla y le pedía a mamá que lo acompañara y mamá se sentaba a su lado y la veía con él y entonces veía a papá sollozar y lo oía decirle No sabes cúantos de mis amigos murieron allí y mamá cruzaba los dedos para que la serie terminara y para que papá pudiera estar en paz (JACOBS, 1997, 136).

Está claro, por tanto, que la autora escribe sus páginas con la intención de pretender saldar en cierto modo una deuda con un hombre especial que llevó por toda su vida huellas lacerantes en su interior, sea por el dolor sufrido por la experiencia del combate, sea por el sentimiento de culpa que caracterizó a los combatientes del bando de los perdedores. A este propósito, de hecho, Emile Jacobs, al ser entrevistado en ocasión de la película documental Extranjeros de sí mismos, declara todo su sentimiento 


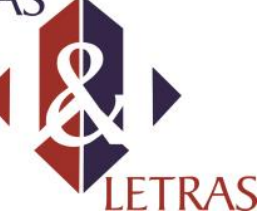

de frustración. "Estoy tratando de recordar", afirma el ex-soldado, "si puedo ofrecer algo más o algo distinto. Pero soy un fracasado, yo no creo que ustedes puedan querer nada de mí. No tengo nada que ofrecer" (RIOYO, LÓPEZ-LINARES, 2001). La sensación de decepción que emerge de las palabras de Jacobs se configura como consecuencia de un recuerdo doloroso que está grabado profundamente en su memoria. La cultura de la humillación del vencido lleva al aislamiento de los soldados derrotados: sobre ellos recaen sentimientos de vergüenza y culpabilidad que se convierten en profundos trastornos psicológicos. "Significa que el excombatiente derrotado tiene que soportar, además del destrozo moral que le han generado las terribles experiencias de los frentes de combate", afirma Ruiz-Vargas, "la vergüenza y humillación social por su condición de vencido" (RUIZ-VERGAS, 2006, 24). En el caso de Emile Jacobs, el dolor que transpira su testimonio parece originarse principalmente por la idea de no haber hecho bastante para combatir al bando vencedor de la contienda.

Por último, al recordar la historia personal de Emile Jacobs parece interesante tener en cuenta además el aspecto de su identidad. Si es verdad que Jacobs fue americano de pleno derecho por haber nacido en los Estados Unidos, también hay que considerar que fue hijo de una familia de inmigrantes libaneses asentados en América a finales del siglo XIX. Por tanto, Emile encarna la tipología de sujeto que se podría insertar dentro de un grupo identitario clasificado, hoy en día, con el marbete de ‘inmigrantes de segunda generación'. "Los hijos de inmigrantes", sostiene Handri, "parecen condenados a ubicarse en un «entre dos», entre dos países, dos culturas, dos idiomas, incluso, a veces, entre dos religiones" (HANDRI, 2008, 2). En efecto, durante el proceso de construcción de su identidad, testimoniado en varios pasajes de la novela, Jacobs se muestra capaz de identificarse con ambas las dimensiones culturales, precisamente por recibir la influencia tanto de su familia libanesa como de la cultura americana. Por esta razón, a través del recuerdo de la experiencia bélica de Emile Jacobs en la Guerra Civil, se evoca también la importante contribución que el mundo árabe ofreció a la República. A pesar del silencio que rodeó por mucho tiempo el tema de la participación de los árabes en las Brigadas Internacionales, recientes investigaciones han podido comprobar, a través de informes recaudados en algunos archivos rusos, la presencia efectiva de voluntarios árabes en las filas republicanas: entonces, junto a militantes de muchas otras nacionalidades, está confirmado por la documentación que en el conflicto también combatieron argelinos, tangerinos, marroquíes, egipcios, sirios, palestinos, saudíes y, por supuesto, libaneses. Según un 


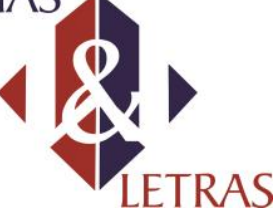

e-ISSN: 1981-4755

DOI: $10.5935 / 1981-4755.20170016$

estudio de Bofarull, que recoge los análisis de Andreu Castells de 1973, la cifra total de los "moros" implicados en el conflicto para defender la República española se aproximaría a 716 (BOFARULL, 2004, 132) .

Del relato se deduce cuánto le debió Emile Jacobs a su país de origen: al irse voluntario a España para combatir en la guerra civil, el joven rompió secamente con la línea política adoptada por los Estados Unidos que disponía una posición de absoluta no interferencia en los asuntos internos españoles. Por consecuencia, cuando volvió de la guerra en 1939, las autoridades norteamericanas le condenaron a la retención del pasaporte. Siguió para Jacobs un periodo de profunda inseguridad laboral y económica que se resolvió únicamente gracias a su patria originaria que, en ocasión de la Exposición Internacional de Nueva York de 1939, le brindó la oportunidad de conseguir el puesto de Director del Pabellón de la República del Líbano. La nación libanesa, al fin y al cabo, le proporcionó a su hijo estadounidense la posibilidad de terminar con la vida de 'antes' para dar comienzo a un proyecto con nuevos contornos: durante la feria neoyorquina, de hecho, conoció a su futura esposa (ella también de origen libanés) y junto a ella empezó a predisponer la construcción de una futura dimensión familiar mexicano-libanesa de la que formará parte, por supuesto, la misma autora. En fin, Las hojas muertas se configura como el medio que Bárbara Jacobs utiliza para rendir tributo al legado sorprendente de un individuo solo aparentemente común: para conseguir su objetivo, la autora convierte al padre en un personaje memorable cuyo heroísmo está aún más enfatizado por la perspectiva de una niña narradora que modifica su estatus de vencido en el de triunfador. En su novela, la escritora mexicana abandona el camino del olvido para emprender el complejo trabajo de la memoria: recoge los recuerdos de su padre para transmitirlos por medio de su literatura. La acción de testimoniar rompe el silencio y dispone finalmente la experiencia vivida al alcance de todos.

\section{REFERENCIAS}

AKMIR, Abdeluahed, "Introducción", en Akmir, Abdeluahed (ed.), Los árabes en América Latina: Historia de una emigración. Madrid, Siglo XXI, 2009, 1-10.

BADOS CIRIA, Concepción, "Las hojas muertas: escrito en/con el nombre del padre", Revista de Literatura Hispanomericana, 34, 1997, 129-139.

BEN SALEM, Abdelatif, "La participación de los voluntarios árabes en las Brigadas Internacionales. Una memoria rescatada", en Alcantud, José Antonio (ed.), Marroquíes en la guerra civil española: campos equívocos, Granada, Anthropos, 2003, 111-131.

\footnotetext{
${ }^{5}$ Para más información sobre la presencia de voluntarios de origen árabe en la Guerra Civil española, se remite al estudio de Abdelatif Ben Salem (2003).

Volume 18

Número 40
} 


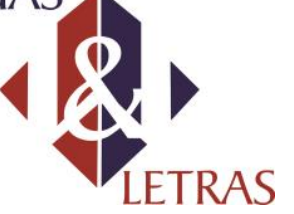

BOFARULL, Salvador, "Brigadistas árabes en la Guerra de España”, Nación Árabe, 52, 2004, 121-134.

CÁNOVAS, Rodrigo, "Letras mexicanas libanesas: Bosquejando el cedro americano", Acta literaria, 38, 2009, 9-26.

HADJ HANDRI, Nathalie, "La identidad mutante. La construcción de la identidad en los hijos de los inmigrantes", Documentación social, 151, 2008, 35-48.

JACOBS, Bárbara, Las hojas muertas, Madrid, Alfaguara, 1997.

JACOBS, Bárbara, "Una pequeña historia personal", en "Almalafa y caligrafía. Literatura de origen árabe en América Latina", Hostos Review, 7, 2010, 186-197.

JELIN, Elizabeth, Los trabajos de la memoria, Madrid-Buenos Aires: Siglo XXI Editores, 2002.

MORENO-NUÑO, Carmen, Las huellas de la Guerra Civil. Mito y trauma en la narrativa de la España democrática, Madrid, Ediciones Libertarias, 2006.

PADILLA, Miriam, "Bárbara Jacobs celebra 25 años de Las hojas muertas", El Informador, 25/11/2012, disponible en http://www.informador.com.mx/fil/2012/420052/6/barbara-jacobs-celebra-25-anos-delas-hojas-muertas.htm.

RIOYO, Javier, LÓPEZ-LINARES, José Luis, Extranjeros de sí mismos, Cero en Conducta S.L., 2001.

RUIZ-VARGAS, José María, "Trauma y memoria de la Guerra Civil y de la dictatura franquista", Hispania Nova, Revista de Historia Contemporánea, 6, 2006, 3-39.

Data de recebimento: 01/05/2017

Data de aprovação: 31/08/2017 